\title{
The influence of sex, age, and handedness on corpus callosum morphology: A meta-analysis
}

\author{
NAOMI R. DRIESEN and NAFTALI RAZ \\ University of Memphis, Memphis, Tennessee
}

\begin{abstract}
Initial observations linking variation in the human corpus callosum (CC) to handedness and sex have inspired a number of investigations of individual differences in CC size and morphology. In this quantitative review, we summarize the findings from these studies and assess the magnitude of sex, age, and handedness-related variations in the size of the CC. Meta-analysis of the 43 studies indicated that although absolute CC and splenial area are larger in men than in women, CC area adjusted for brain size was larger in women. Left-handers possess slightly larger CCs than do right-handers, and CC area decreases slightly with age. The implications of these findings for theories relating cerebral laterality to sex, age, and handedness are discussed.
\end{abstract}

Initial observations of size differences in the corpus callosum (CC) related to sex (De Lacoste-Utamsing \& Holloway, 1982) and handedness (Witelson, 1985) have inspired numerous studies exploring possible sex and handednessrelated variations in this structure. The $\mathrm{CC}$ is the major white matter tract connecting the cerebral hemispheres. Its fibers establish primarily homotopic interhemispheric connections organized along an anterior-posterior gradient. Histological studies in primates and humans indicate that the rostrum and genu of the $\mathrm{CC}$ connect anterior frontal areas, the isthmus parietal and posterior frontal areas, and the splenium temporal and occipital cortex (LaMantia \& Rakic, 1990; Pandya \& Seltzer, 1986). Most of the fibers in the CC appear to connect cortical association areas rather than primary cortical areas or subcortical structures (LaMantia \& Rakic, 1990).

Early investigators of hand and sex-related variations in the CC placed their findings within the context of lateralization. De Lacoste-Utamsing and Holloway (1982) found that women possess somewhat larger splenia than do men $(p<.08)$. They hypothesized that these sex differences reflected reduced hemispheric specialization for visuospatial skills. A subsequent report (Holloway \& De Lacoste, 1986) indicated that women's overall CC area was larger than that of men and that this sexual dimorphism might be related to gender differences in cognitive performance. Similarly, Witelson (1985) found that individuals with consistent righthand preference have smaller CCs than do those without. She speculated that this difference reflected reduced lateralization of function in the former group. These hypotheses linking hand and sex differences in the $\mathrm{CC}$ to variations in lateralization of function have gained additional

This project was supported in part by National Institute on Aging Grant AG-11230 to N.R., and by the Center for Applied Psychological Research of the Department of Psychology, University of Memphis. Correspondence should be addressed to N. R. Driesen or N. Raz, Department of Psychology, University of Memphis, Memphis, TN 38152 (email: driesenn@msuvxl.memphis.edu or razn@msuvxl.memphis.edu). support from reports indicating that women possess less lateralized brains than do men (see Bryden, 1982; Kimura, 1987; McGlone, 1980, for reviews) and that people who are not consistent right-handers deviate from lateralization patterns typical for those who are (see Hellige, 1993, for a review).

Since the early autopsy studies (De Lacoste-Utamsing \& Holloway, 1982; Witelson, 1985), a number of researchers have investigated variations in the $\mathrm{CC}$ of sex and handedness groups. The development of magnetic resonance imaging (MRI) has aided this endeavor, because the $\mathrm{CC}$ is easily visualized and measured on MRI scans. However, studies of individual differences in the $\mathrm{CC}$ have produced conflicting results and settled few controversies about the existence of sex and handedness effects.

Even if consistent links could be established, the functional implications of variations in CC size are unclear. De Lacoste-Utamsing and Holloway (1982) and Witelson (1985) shared a common assumption that a larger CC indicated more fibers connecting the hemispheres and thus reduced lateralization. Empirical support for this proposition is meager. In a series of 15 adult rhesus monkeys, LaMantia and Rakic (1990) observed no relationship between the number of axons and CC size. A recent study of fiber composition in the human corpus callosum (Aboitz, Scheibel, Fisher, \& Zaidel, 1992), however, suggested that the number of relatively small callosal fibers increases with increases in $\mathrm{CC}$ area. These smaller fibers are believed to connect association rather than primary areas of the cortex (LaMantia \& Rakic, 1990). The fact that Aboitz and colleagues could not assess fibers whose diameters, before shrinkage of autopsy sections, were less than $.6 \mu \mathrm{m}$, though, limits the generalizability of their findings.

Although changes in the size or density of callosal axons may increase interhemispheric transfer, such alterations could also reduce communication between the hemispheres. Some authors (e.g., Dennis, 1976; Kinsbourne, 1982; Zaidel, Clarke, \& Suyenobu, 1990) have suggested that the CC may actually inhibit communication between 
Table 1

Correlations Between Brain Weight and Corpus Callosum

\begin{tabular}{lcc}
\hline \multicolumn{1}{c}{ Study $^{\mathrm{a}}$} & $r$ & $n$ \\
\hline Bean $(1906)^{\mathrm{b}}$ & .62 & 45 \\
Mall $(1909)^{\mathrm{b}}$ & .76 & 17 \\
${\text { Weber }(1986)^{\mathrm{c}}}^{\mathrm{c}}$ & $<.003$ & 36 \\
Demeter $(1988)^{\mathrm{d}}$ & .26 & 33 \\
${\text { Witelson }(1989)^{\mathrm{e}}}_{\text {Aboitz }(1992)}$ & .48 & 50 \\
& .32 & 40 \\
\hline
\end{tabular}

aEach study is indicated by first author's name and the year of publication. bWhite subjects only, as reported in Witelson (1989). Less confidence should be placed in the results of the Bean and Mall studies than the others because their treatment of postmortem specimens did not meet modern-day standards. cDerived from a regression equation, with age and brain weight as covariates. dCerebellum and brain stem at and below level of mesencephalon removed. ' Cerebrum weight only.

the hemispheres. Thus, persons with relatively large CCs would be expected to be less lateralized than those with smaller CCs. Furthermore, some animal studies of the CC indicate that environment may influence $\mathrm{CC}$ size and myelination (Juraska \& Kopcik, 1988).

Individual variations in brain size further complicate efforts to understand the functional implications of larger CCs, particularly as regards possible sexual dimorphism in this structure. In general, brain size is correlated with body size indices such as height. Men's brains are more massive than women's by an average of $150-200 \mathrm{~g}$ (Peters, 1988), and there appears to be a moderate correlation (me$\operatorname{dian} r=.40$ ) between brain weight and CC size, as is demonstrated in Table 1. Sex differences in CC area may imply the need to connect greater areas of cortex rather than differences in brain laterality or interhemispheric transfer.

By taking into account measures of brain weight or area, researchers have attempted to discover whether sex differences in $\mathrm{CC}$ exceed those expected from group differences in brain size. The most common technique of compensating for brain size differences has been to divide raw $\mathrm{CC}$ area measures by midsaggital brain area. These results are difficult to interpret because of the undesirable psychometric properties of ratio variables (Cohen \& Cohen, 1983).

In attempts to relate handedness to CC size, a particular problem has been the definition of handedness groups. Individuals vary in the consistency of their hand preference across tasks. Consistent left-handedness is relatively rare, existing in about $4 \%$ of the population, whereas consistent right-handedness is relatively common, present in about $66 \%$ of the population (Annett, 1972). In studies of handedness and the $\mathrm{CC}$, most investigators have divided their samples into consistent right-handers and nonconsistent right handers, with mixed and left-handers included in the latter group. Consistent left-handers in small samples are relatively rare, and investigators have argued that the presence of chronic left-handers in a sample may explain discrepancies between studies (Wittelson, 1992). At this point, it is unclear whether the direction of hand preference and/or its consistency is most closely associated with divergent patterns of cerebral organization.
A possible confounding variable in studies of sex and handedness groups is age (Allen, Richey, Chai, \& Gorski, 1991). There are a number of reasons to suspect that the size of the CC may decrease with age in the adult years. Brain weight and volume reductions, gyral atrophy, and ventricular dilation in aging have been well documented in the postmortem and neuroimaging literature (Kemper, 1994; Raz, in press). This process is most pronounced in cortical association areas, the very same areas that are most densely connected by callosal fibers. In addition, there are age-related reductions in myelination (Ansari \& Loch, 1975; Kirkpatrick \& Hyman, 1987), which would be expected to affect the CC, a heavily myelinated structure. Other variables that might help explain inconsistent results among studies include differences between autopsy and MRI methods of ascertaining CC area and, in studies that consider subsections of the $\mathrm{CC}$, variations in methods for its division.

Our aim in the present review is to assess the possible existence and magnitude of sex, age, and handedness variations in the CC through meta-analysis (Glass, McGaw, \& Smith, 1981; Hedges \& Olkin, 1985). In this analytic approach, individual studies serve as the units of analysis, much as subjects do in typical experimental investigations. The dependent variable, the effect size, quantifies the magnitude of the difference between two groups. Specifically, the effect size, $d$, is the difference between the group means divided by their pooled standard deviation. Metaanalysis allows an objective assessment of congruities and discrepancies between studies and a basis for evaluating hypotheses about effect size differences between research reports. In this review, we use meta-analysis to explore the following questions regarding age, handedness, and sex effects in the CC:

1. Does CC area differ between the sexes?

2. Does adjustment for brain size result in different estimates of these hypothesized differences?

3. Is the area of the splenium larger in women than in men?

4. Do postmortem and MRI studies diverge in estimates of the magnitude of sex differences?

5. Is the area of the CC smaller in right-handers than in left- or mixed-handed individuals?

6 . Does the area of the CC vary with age?

\section{METHOD}

\section{Study Selection}

We considered all journal articles in which postmortem or MRI was used to obtain $\mathrm{CC}$ area measurements of normal volunteers or neurological or medical controls. Both studies that included raw and studies that included normalized (i.e., raw $\mathrm{CC}$ area divided by midsaggital brain area) estimates of $\mathrm{CC}$ area were included. In investigations that compared normal controls with another group of neurological or psychiatric patients, only data from the former group were considered. All studies that had information sufficient to compute an effect size for gender, age, or handedness were included in the final sample. When several classifications of handedness were used in a study, we pooled data to yield a comparison between righthanders and mixed-and/or left-handers. When two studies emerged 
from the same laboratory with information insufficient to determine whether the samples were independent, we took the conservative approach of using only effect sizes computed from the study with the largest sample size. Of the 43 studies included in the meta-analysis. three were in Japanese, one was in German, and the rest were in English.' Dates of publication ranged from 1906 to 1994.

\section{Variables Analyzed}

To examine the questions posed in the introduction, we coded a number of study characteristics. Tabulation of relevant characteristics was limited by which study attributes were consistently reported across studies. For example, time from death to autopsy and time from autopsy to $\mathrm{CC}$ measurement are clearly relevant variables for postmortem studies. However, these variables were not consistently reported in the 10 postmortem studies included in the meta-analysis. The coded variables can readily be divided into those describing subjects and those pertaining to methods.

I. Subject Variables

A. Sample size.

B. Number of men and women.

C. Age: When available, the mean age of the sample was used. If studies reported only a range of ages, the midpoint of the age range was used.

D. Standard deviation of age: The standard deviation of age for each sample was recorded when available.

E. Handedness: The number of right-, left-, and mixed-handed individuals in the sample was recorded.

F. Origin of sample: Normal volunteers, pseudoneurological controls, or medical controls. If investigators reported a sample of normal volunteers and pseudoneurological controls or normal volunteers and medical controls, the sample was coded as pseudoneurological controls and medical controls, respectively.

II. Method Variables

A. Technique: Postmortem versus MRI.

B. MRI acquisition sequence: $T_{1}$-weighted, $T_{2}$-weighted, proton density, or inversion recovery.

\section{STATISTICAL ANALYSIS}

To estimate gender and handedness effect sizes, we computed $d$ (Cohen, 1977). When possible, $d$ was calculated directly from means and standard deviations or from individual data points read from relevant graphs. If this information was unavailable, $d$ was derived from inferential statistics $\left(t, F, \chi^{2}\right)$. We used Hedges's correction (Hedges $\&$ Olkin, 1985) to adjust $d$ for small sample sizes. Although in this meta-analysis weighted and unweighted average effect sizes yielded similar estimates, we report average effect sizes weighted by study sample size (i.e., $d$.; Hedges \& Olkin, 1985).

The measure of effect size for age was Pearson correlations. Whenever possible, we recorded relevant correlations reported in the article or computed them from individual data points read from graphs. Five of the 19 studies with information relevant to aging effects simply reported the correlation between aging and $\mathrm{CC}$ as nonsignificant without supplying descriptive or inferential statistics (Aboitz, Scheibel, \& Zaidel, 1992; Hauser, Dauphinais, Berrettini, DeLisi, Gelernter, \& Post, 1989; Mathew et al., 1985; Uematsu \& Kaiya, 1988; Woodruff, Pearlson, Geer, Barta, \& Chilcoat, 1993). Because of the large proportion of studies with this problem, the effect size for age was computed in two ways. In the first method, the effect size of findings simply reported "not significant" was assumed to be zero. In the second method, these findings were assumed to have just missed statistical significance, the table value of $r$ for a given number of degrees of freedom was accepted, and the corresponding $d$ was used. These methods provided a low and a high estimate of average effect size, respectively. Characteristics of the 43 studies included in the metaanalysis are displayed in Table 2. Effect sizes for raw area measures appear in Table 3.

A test for homogeneity of effect sizes (Hedges \& Olkin, 1985) was conducted for each group of studies. The null hypothesis for this test is that the effect sizes are homogeneous and differences between effect sizes are simply random sampling variations. When the null hypothesis is rejected, it is assumed that there are systematic differences between studies that yield disparate effect sizes.

\section{RESULTS}

\section{Sex and $C C$ Area}

The mean effect size for the 36 studies comparing the corpus callosum area of men and women was $d .=.27$, with a $95 \%$ confidence interval (CI 95\%) extending from .19 to .36 . This effect size indicates that approximately $21 \%$ of the combined distribution of men and women is nonoverlapping. The median $\mathrm{CC}$ area for men stands at about the 62 nd percentile for women. A test for homogeneity of effect size (Hedges \& Olkin, 1985) failed to reject the null hypothesis $\left[Q_{\mathrm{T}}(35)=46.83\right.$, n.s.]. Thus, differences in effect sizes among studies may be simply the result of random sampling variations.

Comparisons between postmortem versus MRI studies were not statistically significant $[F(1,34)=1.04$, n.s. $]$. Among the 14 studies of sex differences in $\mathrm{CC}$ area that also reported handedness information, the correlation between

Table 2

Characteristics of Studies Included in Meta-Analysis

\begin{tabular}{|c|c|c|c|c|}
\hline Subject Variables & $M$ & Range & $n$ & $\%$ \\
\hline Sample Size & 56 & $12-153$ & & \\
\hline Percentage males $(\%)$ & 53 & $27-100$ & & \\
\hline Age Mean (years) & 43 & $25-78$ & & \\
\hline Age Standard Deviation (years) & 13 & $5-21$ & & \\
\hline \multicolumn{5}{|l|}{ Handedness } \\
\hline Right-handed only & & & 6 & 14 \\
\hline Mixed sample & & & 12 & 28 \\
\hline Not reported & & & 25 & 58 \\
\hline \multicolumn{5}{|l|}{ Sample Origin } \\
\hline Normal volunteers & & & 21 & 49 \\
\hline Pseudoneurological controls & & & 9 & 21 \\
\hline Postmortem & & & 11 & 26 \\
\hline Not reported & & & 2 & 5 \\
\hline \multicolumn{5}{|l|}{ Method Variables } \\
\hline Postmortem & & & 11 & 26 \\
\hline Magnetic resonance imaging & & & 32 & 74 \\
\hline $\mathrm{T}_{1}$-weighted & & & 24 & 75 \\
\hline $\mathrm{T}_{2}$-weighted & & & 1 & 3 \\
\hline Inversion recovery & & & 5 & 16 \\
\hline Not reported & & & 2 & 6 \\
\hline
\end{tabular}


Table 3

Effect Sizes Derived From Absolute Area Measures for Studies Included in Meta-Analysis

\begin{tabular}{|c|c|c|c|c|c|c|}
\hline \multirow[b]{2}{*}{ Study* } & \multirow[b]{2}{*}{$N(\mathrm{M} / \mathrm{F})$} & \multirow[b]{2}{*}{ Method $\dagger$} & \multicolumn{2}{|c|}{$d$ for Sex } & \multirow[b]{2}{*}{ Handedness } & \multirow[b]{2}{*}{ Age, CC Area } \\
\hline & & & CC Area & Splenial Area & & \\
\hline Bean (1906) & $149(107 / 42)$ & PM & .68 & .49 & & -.03 \\
\hline Mall (1909) & $103(80 / 23)$ & PM & .65 & & & \\
\hline De Lacoste-Utamsing (1982) & $14(9 / 5)$ & PM & -.03 & -.97 & & \\
\hline Mathew (1985) & $18(10 / 8)$ & MRI & & & & n.s. \\
\hline Nasrallah (1986) & $4 l(21 / 20)$ & MRI & .94 & & .41 & \\
\hline Weber (1986) & $36(18 / 18)$ & PM & .25 & .07 & & .00 \\
\hline Kertesz (1987) & $104(51 / 53)$ & MRI & n.s. & & .16 & \\
\hline Simon (1987) & $48(17 / 31)$ & MRI & .84 & & & -.01 \\
\hline Uematsu (1988) & $17(17 / 0)$ & MRI & & & & n.s. \\
\hline Byne (1988) & $37(15 / 17)$ & MRI & 67 & -.11 & & -.17 \\
\hline Demeter (1988) & $33(22 / 11)$ & PM & .39 & .00 & & -.02 \\
\hline O'Kusky (1988) & $50(26 / 24)$ & MRI & .32 & & -.57 & \\
\hline Takeda (1988) & $153(81 / 72)$ & MRI & -.04 & & & -.23 \\
\hline Weiss (1988) & $46(20 / 26)$ & MRI & .03 & .23 & & \\
\hline S. Clarke (1989a) & $46(27 / 19)$ & PM & .90 & .26 & & -.27 \\
\hline S. Clarke (1989b) & $12(5 / 7)$ & MRI & -.19 & -.26 & & \\
\hline Hauser (1989) & $25(14 / 11)$ & MRI & .24 & & & n.s. \\
\hline Hayakawa (1989) & $26(13 / 13)$ & MRI & .55 & & & \\
\hline Witelson (1989) & $50(15 / 35)$ & PM & & & -.57 & \\
\hline Yoshii (1989) & $64(32 / 32)$ & MRI & .05 & .32 & -.11 & \\
\hline De Lacoste (1990) & $69(36 / 33)$ & PM & -.12 & & & \\
\hline Elster (1990) & $120(60 / 60)$ & MRI & .25 & .11 & & \\
\hline Going (1990) & $33(17 / 16)$ & PM & .28 & .64 & & \\
\hline Lewine (1990) & $91(67 / 24)$ & MRI & .80 & & & \\
\hline Okamoto (1990) & $27(17 / 10)$ & MRI & .59 & .80 & & \\
\hline Raine (1990) & $18(9 / 9)$ & MRI & .18 & & & \\
\hline $\operatorname{Raz}(1990 a)$ & $28(15 / 13)$ & MRI & .32 & .56 & & .22 \\
\hline $\operatorname{Raz}(1990 b)$ & $44(12 / 32)$ & MRI & .58 & .82 & & -.08 \\
\hline Allen (1991) & $122(61 / 61)$ & MRI & .10 & -.17 & & .19 \\
\hline Doraiswamy (1991) & $35(15 / 20)$ & MRI & .17 & & & -.42 \\
\hline Witelson (1991) & $62(23 / 39)$ & PM & .46 & & & .29 \\
\hline Emory (1991) & $40(20 / 20)$ & MRI & .13 & & & \\
\hline Gunther (1991) & $31(19 / 12)$ & MRI & & & & -.07 \\
\hline Aboitz (1992) & $40(20 / 20)$ & PM & .50 & .18 & & n.s. \\
\hline Laissy (1993) & $124(63 / 61)$ & MRI & .31 & & & \\
\hline Steinmetz (1992) & $52(26 / 26)$ & MRI & .05 & & .10 & \\
\hline Weiss (1993) & $46(20 / 26)$ & MRI & & & & -.53 \\
\hline Woodruff (1993) & $44(34 / 10)$ & MRI & .42 & .23 & & n.s. \\
\hline Burke (1994) & $97(38 / 59)$ & MRI & -.14 & .01 & & -.24 \\
\hline J.M. Clarke (1994) & $60(30 / 30)$ & MRI & .21 & .27 & -.35 & \\
\hline $\operatorname{Raz}(1994)$ & $62(32 / 30)$ & MRI & -.08 & & & -.39 \\
\hline
\end{tabular}

Note-Effects that were reported as nonsignificant with information insufficient for calculating an exact effect size are designated as n.s. *Each study is indicated by first author's name and the year of publication. †PM, postmortem; MRI, magnetic resonance imaging.

the percentage of right-handers in the sample and effect size for sex did not reach statistical significance $[r(12)=$ -.33 , n.s.]. Similarly, means and standard deviations of age did not correlate with effect size $[r(31)=-.16$, n.s., and $r(21)=-.06$, n.s., respectively].

In contrast to the average effect size for raw area measures, the average effect size for the 11 studies that used normalized CC measures $(d .=-.26)$ indicated that, for their brain size, women's callosal areas were actually larger than those of men. The CI $95 \%$ for this effect size extends from -.43 to -.08 . It excludes zero and does not overlap with that of the raw area measures. The null hypothesis of homogeneity was not rejected $\left[Q_{\mathrm{T}}(10)=18.01\right.$, n.s.]. The effect sizes from the normalized measures are displayed in Table 4, and, when available, they are compared with effect sizes derived from raw area measures on the same sample.

\section{Sex and Splenial Area}

The average effect size for the 21 studies comparing splenial area in men and women was .20. The effect size for De Lacoste-Utamsing and Holloway (1982) was an outlier by Tukey's (1977) criterion (i.e., that data point fell farther than 1.5 times the interquartile range from the median). Removal of this study yielded an average effect size of .21 . The study was deleted from all subsequent analyses.

This average effect size indicates that splenial area, like overall CC area, is larger in men than in women. The sex difference in area appears smaller in the splenium than in the entire CC, although the CI 95\% for the splenium overlaps with that for the CC (.09-.34 and .19-.36, respectively). Approximately $14.7 \%$ of the distributions of men and women have nonoverlapping splenial areas, and the median male splenial area is at the 58th percentile for 
Table 4

Comparison of Effect Sizes Derived From Normalized Versus Absolute Area Measures: Sex Differences in Corpus Callosum (CC) Area

\begin{tabular}{lcc}
\multicolumn{1}{c}{ Study* } & $d_{\text {norm }}{ }^{\dagger}$ & $d_{\text {raw }} \ddagger$ \\
\hline Nasrallah (1986) & .23 & .94 \\
Hauser (1989) & -.11 & .24 \\
Yoshii (1989) & -1.05 & .05 \\
Elster (1990) & -.38 & .25 \\
Raine (1990) & 0 & .18 \\
Raz (1990a) & -.40 & .32 \\
Raz (1990b) & 0 & .58 \\
Duara (1991) & .13 & .13 \\
Emory (1991) & -.33 & \\
Habib (1991)§ & .31 & -.08 \\
Raz (1994) & -.40 & \\
\hline
\end{tabular}

*Each study is indicated by first author's name and the year of publication. 'Effect size $(d)$ derived from normalized $\mathrm{CC}$ measures. $\ddagger$ Effect size $(d)$ derived from raw $\mathrm{CC}$ area measures. ${ }^{\S}$ Investigators magnified magnetic resonance imaging scans so that the midsaggital area was equal for all subjects and then measured the $\mathrm{CC}$.

women. The null hypothesis of homogeneity of effect size could not be rejected $\left[Q_{\mathrm{T}}(19)=25.27\right.$, n.s.]. Not enough studies were available to effectively compare raw and normalized measures of splenial area.

\section{Handedness}

Seven studies in which the effects of handedness on CC area were examined yielded an average effect size of $d$. = -.13 (CI $95 \%=-.23$ to -.02 ). Thus, left-handers had larger $\mathrm{CC}$ areas than did right-handers. The average effect size has approximately the same magnitude as does the difference between men and women in CC area. The test of homogeneity of variance indicated that there was no systematic variation between studies $\left[Q_{\mathrm{T}}(6)=10.18\right.$, n.s.], although the power of that test was rather limited.

\section{Age}

The effect size for age was computed in two ways. In the "low estimate" method, the effect size of findings simply reported "not significant" was assumed to be zero. In the "high estimate" method, these findings were assumed to have just missed statistical significance and the corresponding $d$ was used. The 21 studies of age and CC area yielded low and high effect estimates of the average correlation between age and CC of $r=-.12$ and $r=-.16$. Correlation coefficients were converted to $d \mathrm{~s}$ to allow for computation of the homogeneity of variance statistic. The null hypothesis of homogeneity was rejected by either the low or the high estimate method $\left[Q_{\mathrm{T}}(20)=44.4, p<.05\right.$ or $\left.Q_{\mathrm{T}}(20)=49.7, p<.05\right]$. The average effect sizes for the two methods were $d .=-.24(\mathrm{CI} 95 \%-.12$ to -.36$)$ and $d .=-.33$ (CI $95 \%-.22$ to -.45 ), respectively. Because the low and high estimates were similar in magnitude, the low, or more conservative, estimate was used for all subsequent analyses. The correlations between study $r \mathrm{~s}$ and mean age and mean age standard deviation of study sample were $r(19)=-.34$, n.s., and $r(16)=-.23$, n.s., respectively.

\section{DISCUSSION}

The results of this meta-analysis indicate that the area of the whole $\mathrm{CC}$ and the splenium is slightly larger in human males than in human females. In the case of whole CC, when sex differences in brain size are taken into account, the direction of the differences is reversed. In addition, the $\mathrm{CC}$ is smaller in right-handers than in non-right-handers. Younger subjects have greater $\mathrm{CC}$ areas than do their elders, raising the possibility that the $\mathrm{CC}$ decreases with age. Longitudinal studies would be necessary to effectively test the latter hypothesis. Analytic techniques indicate that differences between studies of sex and handedness and CC area or sex and splenial area are a result of random sampling differences, rather than systematic variations. The opposite appears to be true for aging studies.

Our present knowledge of the relationship between $\mathrm{CC}$ size and brain connectivity constrains efforts to interpret observations of greater CCs in particular groups. Among studies that compare men and women, sexual differences in brain size further complicate this issue. When investigators control for this discrepancy via normalization procedures, women's CCs appear to be somewhat larger than men's. It might be concluded from this that once intergroup differences in brain size are considered, women's CC area exceeds men's.

However, the differences in effect sizes derived from raw and normalized $\mathrm{CC}$ area measures may be due simply to the mathematical properties of ratio measures. $\mathrm{CC}$ areas are typically less than one tenth the size of midsaggital brain areas. For example, Allen, Richey, Chai, and Gorski (1991) reported that adult males had an average $\mathrm{CC}$ area of $6.87 \mathrm{~cm}^{2}$ and midsaggital brain area of $92.96 \mathrm{~cm}^{2}$ and that adult females had average CCs of $6.80 \mathrm{~cm}^{2}$ and midsaggital brain area of $88.57 \mathrm{~cm}^{2}$. Thus, when researchers divide $\mathrm{CC}$ area by midsaggital brain area, they are dividing a small number by a number about 10 times its size. Hence, the denominator dominates the magnitude of the ratio. In this situation, the smaller ratio variable will be the one whose numerator is divided by the largest quantity. Therefore, men, simply by virtue of their larger brains, would appear to have smaller CCs than women, when ratio indices are used.

The analysis of covariance, with a measure of brain size as the covariate, provides a more appropriate method of considering the possible correlation between $\mathrm{CC}$ and brain size. In this approach, men and women's average $\mathrm{CC}$ area would be compared after adjustment for the correlation between brain and CC size in the entire sample. This statistical technique would be valid only if the relationship between brain and CC measures is similar in men and women--in other words, if there is no statistically significant interaction between gender and brain size.

Splenial area in men is larger than in women, as is their overall raw $\mathrm{CC}$ area. This conclusion may be surprising to many readers because it directly contradicts De Lacoste-Utamsing and Holloway's (1982) original findings. In this regard, it is important to note that their report 
is a statistical outlier among studies of sex and splenial area. Its large effect size $(d=-.97)$ is greater than, for example, the difference between the heights of 13- and 18year-old girls (Cohen, 1977). Given De Lacoste-Utamsing and Holloway's small sample size $(N=14)$, a few anomalous individuals could easily have skewed their results.

The present analysis indicates that differences between studies of sex and CC or splenial area are a result of random sampling differences, rather than systematic variations. The caveat, however, is that small sample sizes limit the power to reject the null hypothesis of homogeneity. Our inability to find statistically significant relationships between effect sizes and various study characteristics also suggests that systematic differences between studies contribute little to variations between them. Interestingly, despite great improvements in methods of investigation, studies from the turn of the century (Bean, 1906; Mall, 1909) yield effect sizes similar to those found in more modern studies. The preceding observations must be qualified by considering the small number of studies analyzed and the fact that some potentially important variables were not available for analysis because investigators did not collect and/or report them. For example, researchers often did not include measures of handedness and sometimes failed to report the age range of subjects. Thus, as more studies of CC and sex accrue, other important sources of study variation may well be discovered.

In the case of sex differences in the $\mathrm{CC}$, we were unable to address quantitatively the wide variety of techniques for demarcating the splenium. For example, many investigators use a rule for drawing a straight line from the most anterior to the most posterior part of the $\mathrm{CC}$ and then divide this reference line into fifths (De Lacoste-Utamsing \& Holloway, 1982; Witelson, 1985). The most posterior fifth is then considered the splenium. Other researchers use a curved reference line, such as in the center-of-gravity method adopted by S. Clarke, Kraftsik, Van der Loos, and Innocenti (1989). The diversity of methods used in a relatively small sample of studies did not allow for meaningful quantitative comparisons. However, single studies comparing two or more measurement methods (e.g., Allen et al., 1991; J. M. Clarke \& Zaidel, 1994; Woodruff et al., 1993) have found few differences in the results obtained. Because the splenium is continuous with the rest of the $\mathrm{CC}$, no method is essentially more valid than another. The reliability of the techniques may vary, but with a few notable exceptions (Steinmetz et al., 1992; Witelson, 1989), investigators do not report reliability estimates.

Acceptance of the null hypothesis of homogeneity of variance is particularly suspect in the case of handedness studies because of the small sample size ( $n=7$ studies). Methods of determining handedness group and the range of hand preference present in the subjects (Witelson, 1992) are likely sources of significant variation between studies. A systematic meta-analysis of these differences awaits additional empirical investigations.

The lack of homogeneity in aging studies constrains conclusions concerning age-related variations in $\mathrm{CC}$ area. Given the small number of studies on this topic, rejection of the null hypothesis of homogeneity of variance provides strong evidence of systematic differences between research reports. However, for this same reason, between-study variation could not be meaningfully analyzed. In aging studies, health of subjects and age and sex distribution may be important sources of between-study variability.

In conclusion, a quantitative review of studies exploring individual differences in $\mathrm{CC}$ area indicates that this measure can be meaningfully related to sex, age, and handedness of subjects. These links emerge as consistent but weak. The absolute areas of the $\mathrm{CC}$ and splenium appear to be slightly larger in men than in women. Meta-analysis also indicates that $\mathrm{CC}$ area is smaller in right-handers than in non-right-handers and that the $\mathrm{CC}$ may decrease with age.

Investigators can improve future research on age, sex, and handedness-related differences in the $\mathrm{CC}$ by carefully reporting characteristics of subjects such as age and handedness, and, in postmortem studies, detailing their methods for handling brain samples. Calculation of interrater reliabilities would assist the selection of better methods for quantifying the area of the splenium. Particularly in comparisons of the sexes, analysis of covariance approaches are recommended as a more effective method for considering brain size differences than the ratio indices used in past investigations. However, the behavioral significance of observed neuroanatomical variations remains the ultimate question. First steps in this direction have been taken (see, e.g., Zaidel et al., 1990), and one can expect that accumulation of evidence in this area will resolve at least some of the debates on the relationship between functional lateralization and CC morphology.

\section{REFERENCES}

Aboitz, F., Scheibel, A. B., Fisher, R. S., \& Zaidel, E. (1992). Fiber composition of the human corpus callosum. Brain Research, 598 , 143-153.

Aboitz, F., Scheibel, A. B., \& ZAIDEL, E. (1992). Morphometry of the Sylvian fissure and the corpus callosum with emphasis on sex differences. Brain, 115, 1521-1541.

Allen, L. S., Richey, M. F., Chai, Y. M., \& Gorski, R. A. (1991). Sex differences in the corpus callosum of the living human being. Journal of Neuroscience, 11, 933-942.

ANNETT, M. (1972). The distribution of manual asymmetry. British Journal of Psychology, 63, 343-358.

ANSARI, K. A., \& LoCH, J. (1975). Decreased myelin basic protein content of the aged human brain. Neurology, 25, 1045-1050.

BEAN, R. B. (1906). Some racial peculiarities of the Negro brain. American Journal of Anatomy, 5, 353-432.

BRYDEN, M. P. (1982). Laterality: Functional asymmetry in the intact brain. New York: Academic Press.

Clarke, J. M., \& ZaIDel, E. (1994). Anatomical-behavioral relationships: Corpus callosum morphometry and hemispheric specialization. Behavioural Brain Research, 64, 195-202.

Clarke, S., Kraftsik, R., VAn der Loos, H., \& Innocenti, G. (1989). Forms and measures of adult and developing human corpus callosum: Is there sexual dimorphism? Journal of Comparative Neurology, 280, 213-230.

CoHeN, J. (1977). Statistical power for the behavioral sciences. New York: Academic Press.

CoHEn, J., \& COHEN, P. (1983). Applied multiple regression for the behavioral sciences (2nd ed.). Hillsdale, $\mathrm{NJ}$ : Erlbaum.

De Lacoste-Utamsing, C., \& Holloway, R. L. (1982, June 25). Sexual dimorphism in the human corpus callosum. Science, 216, 14311432. 
DENNIS, M. (1976). Impaired sensory and motor differentiation with corpus callosum agenesis: A lack of callosal inhibition during ontogeny? Neuropsychologia, 14, 455-469.

Glass, G. V., McGAw, B., \& SмITH, M. L. (1981). Meta-analysis in social research. Newbury Park, CA: Sage.

Hauser, P., Dauphinais, I. D., Berrettini, W., DeLisi, L. E., GelernTER, J., \& POST, R. M. (1989). Corpus callosum dimensions measured by magnetic resonance imaging in bipolar affective disorder and schizophrenia. Biological Psychiatry, 26, 659-668.

Hedges, L. V., \& OLKIN, I. (1985). Statistical methods for meta-analysis. Orlando, FL: Academic Press.

HELLIGE, J. B. (1993). Hemispheric asymmetry: What's right and what's left. Cambridge, MA: Harvard University Press.

Holloway, R. L., \& DE Lacoste, C. (1986). Sexual dimorphism in the human corpus callosum: An extension and replication study. Human Neurobiology, 5, 87-91.

JurasKa, J. M., \& KopCIK, J. R. (1988). Sex and environmental influences on the size and ultrastructure of the rat corpus callosum. Brain Research, 450, 1-8.

KEMPER, T. L. (1994). Neuroanatomical and neuropathological changes during aging and in dementia. In M. L. Albert \& E. J. E. Knoepfel (Eds.), Clinical neurology of aging (2nd ed., pp. 3-67). New York: Oxford University Press.

KimURA, D. (1987). Are men's and women's brains really different? Canadian Psychology, 28, 133-147.

KinSBOURNE, M. (1982). Hemispheric specialization and the growth of human understanding. American Psychologist, 37, 411-420.

Kirkpatrick, J. B., \& Hyman, L. A. (1987). White-matter lesions in MR imaging of clinically healthy brains of elderly subjects: Possible pathological basis. Radiology, 162, 509-511.

LaMantia, A. S., \& Rakic, P. (1990). Cytological and quantitative characteristics of four cerebral commissures in the rhesus monkey. Journal of Comparative Neurology, 291, 520-537.

MALL, F. P. (1909). On several anatomical characters of the human brain said to vary according to race and sex, with special reference to the frontal lobes. American Journal of Anatomy, 9, 1-32.

Mathew, R. J., Partain, C. L., Prakash, R., Kulkarni, M. V., Logan, T. P., \& WiLson, W. H. (1985). A study of the septum pellucidum and corpus callosum in schizophrenia with MR imaging. Acta Psychiatrica Scandinavica, 72, 414-421.

MCGLONE, J. (1980). Sex differences in human brain asymmetry: A critical survey. Behavioral Brain Science, 3, 215-263.

Pandya, D. N., \& SElTzer, B. (1986). The topography of commissural fibers. In F. Lepore, M. Ptito, \& H. H. Jasper (Eds.), Two hemispheresOne brain: Functions of the corpus callosum (pp. 47-73). New York: Alan R. Liss.

PETERS, M. (1988). The size of the corpus callosum in males and females: Implications of a lack of allometry. Canadian Journal of Psychology, 42, 313-324.

RAZ, N. (in press). Neuroanatomy of aging brain: Evidence from structural MRI. In E. D. Bigler (Ed.), Handbook of human brain function: Neuroimaging. San Diego, CA: Academic Press.

RaZ, N., Spencer, W., Torres, I. T., \& ACKer, J. D. (1990). Sex and age-related differences in midsaggital areas of the cerebral cortex and corpus callosum: An MRI investigation. Society for Neuroscience Abstracts, 16, 1160 .

Steinmetz, H., Jancke, L., Kleinschmidt, A., Schlaug, G., VolkMANN, J., \& HUANG, Y. (1992). Sex but no hand differences in the isthmus of the corpus callosum. Neurology, 42, 749-752.

TuKEY, J. W. (1977). Exploratory data analysis. Reading, MA: AddisonWesley.

Uematsu, M., \& KaIYA, H. (1988). The morphology of the corpus callosum in schizophrenia: An MRI study. Schizophrenia Research, 1, 391-398.

WITELSON, S. F. (1985, August 16). The brain connection: The corpus callosum is larger in left-handers. Science, 229, 665-668.

Witelson, S. F. (1989). Hand and sex differences in the isthmus and genu of the human corpus callosum: A postmortem morphological study. Brain, 112, 799-835.

WITELSON, S. F. (1992). Cognitive neuroanatomy: A new era. Neurology, 42, 709-713.

Woodruff, P. W., Pearlson, G. D., Geer, M. J., Barta, P. E., \&
Chilcoat, H. D. (1993). A computerized magnetic resonance imaging study of corpus callosum morphology in schizophrenia. Psychological Medicine, 23, 45-56.

Zaidel, E., Clarke, J. M., \& Suyenobu, B. (1990). Hemispheric independence: A paradigm case for cognitive neuroscience. In A. B. Scheibel \& A. F. Wechsler (Eds.), Neurobiology of higher cognitive functions (pp. 297-355). New York: Guilford.

\section{Studies Included in Meta-Analysis}

ABoitZ, F., Scheibel, A. B., \& ZAidel, E. (1992). Morphometry of the Sylvian fissure and the corpus callosum with emphasis on sex differences. Brain, 115, 1521-1541.

AlleN, L. S., Richey, M. F., ChaI, Y. M., \& GoRsKi, R. A. (1991). Sex differences in the corpus callosum of the living human being. Journal of Neuroscience, 11, 933-942.

BEAN, R. B. (1906). Some racial peculiarities of the Negro brain. American Journal of Anatomy, 5, 353-432.

BURKE, H. L., \& YEO, R. A. (1994). Systematic variations in callosal morphology: The effects of age, gender, hand preference and anatomic asymmetry. Neuropsychology, 8, 563-571.

BYNE, W., Bleier, R., \& Houston, L. (1988). Variations in human corpus callosum do not predict gender: A study using magnetic resonance imaging. Behavioral Neuroscience, 102, 222-227.

ClARKE, J. M., \& ZaIDEL, E. (1994). Anatomical-behavioral relationships: Corpus callosum morphometry and hemispheric specialization. Behavioural Brain Research, 64, 195-202.

Clarke, S., Kraftsik, R., Van der Loos, H., \& Innocenti, G. (1989). Forms and measures of adult and developing human corpus callosum: Is there sexual dimorphism? Journal of Comparative Neurology, 280, 213-230.

De Lacoste, M. C., Adesanya, T., \& Woodward, D. J. (1990). Measures of gender differences in the human brain and their relationship to brain weight. Biological Psychiatry, 28, 931-942.

De Lacoste-Utamsing, C., \& Holloway, R. L. (1982, June 25). Sexual dimorphism in the human corpus callosum. Science, 216, 1431-1432.

Demeter, S., Ringo, J. L., \& Doty, R. W. (1988). Morphometric analysis of the human corpus callosum and anterior commissure. Human Neurobiology, 6, 219-226.

Doraiswamy, P. M., Figiel, G. S., Husain, M. M., McDonald, W. M., Shah, S. A., BoyKo, O. B., EllinWOOD, E. H., \& KRISHNAN, K. R. (1991). Aging of the human corpus callosum: Magnetic resonance imaging in normal volunteers. Journal of Neuropsychiatry \& Clinical Neurosciences, 3, 392-397.

Duara, R., Kushch, A., Gross-Glenn, K., Barker, W. W., Jallad, B., Pascal, S., Lowenstein, D.A., Sheldon, J., Rabin, M. LEVIN, B., \& LUBS, H. (1991). Neuroanatomic differences between dyslexic and normal readers on magnetic resonance imaging scans. Archives of Neurology, 48, 410-416.

Elster, A. D., DiPersio, D. A., \& Moony, D. M. (1990). Sexual dimorphism of the human corpus callosum studied by magnetic resonance imaging: Fact, fallacy and statistical confidence. Brain Development, 12, 321-325.

Emory, L. E., Williams, D. H., Cole, C. M., Amparo, E. G., \& Meyer, W. J. (1991). Anatomic variation of the corpus callosum in persons with gender dysphoria. Archives of Sexual Behavior, 20, 409-417.

GoING, J. J., \& Dixson, A. (1990). Morphometry of the adult human corpus callosum: Lack of sexual dimorphism. Journal of Anatomy, 171, 163-167.

Gunther, W., Petsch, R., Steinberg, R., Moser, E., Streck, P., Heller, H., KurTZ, G., \& Hippius, H. (1991). Brain dysfunction during motor activation and corpus callosum alterations in schizophrenia measured by cerebral blood flow and magnetic resonance imaging. Biological Psychiatry, 29, 535-555.

Habib, M., Gayraud, D., Olivia, A., Regis, J., Salamon, G., \& KHALIL, R. (1991). Effects of handedness and sex on the morphology of the corpus callosum: A study with brain magnetic resonance imaging. Brain \& Cognition, 16, 41-61.

Hauser, P., Dauphinais, I. D., Berrettini, W., DeLisi, L. E., ḠelernTER, J., \& POST, R. M. (1989). Corpus callosum dimensions measured by magnetic resonance imaging in bipolar affective disorder and schizophrenia. Biological Psychiatry, 26, 659-668. 
Hayakawa, K., Konishi, Y., Matsuda, T., Kuriyama, M., KoNishi, K., Yamashita, K., OkUmura, R., \& Hamanaka, D. (1989). Development and aging of brain midline structures: Assessment with MR imaging. Radiology, 172, 171-177.

Kertesz, A., Polk, M., Howell, T., \& Black, S. E. (1987). Cerebral dominance, sex and callosal size in MRI. Neurology, 37, 1385-1388.

Laissy, J. P., Patrux, B., Duchateau, C., Hannequin, D., Hugonet, P., Ait-Yahia, H., \& Thiebot, J. (1993). Midsaggital MR measurements of the corpus callosum in healthy subjects and diseased patients: A prospective survey. American Journal of Neuroradiology, 14, 145-154.

Lewine, R. R. J., Gulley, L. R., Risch, S. C., Jewart, R., \& Houpt, J. L. (1990). Sexual dimorphism, brain morphology and schizophrenia. Schizophrenia Bulletin, 16, 195-203.

MALL, F. P. (1909). On several anatomical characters of the human brain said to vary according to race and sex, with special reference to the frontal lobes. American Journal of Anatomy, 9, 1-32.

Mathew, R. J., Partain, C. L., Prakash, R., Kulkarni, M. V., Logan, T. P., \& WILSON, W. H. (1985). A study of the septum pellucidum and corpus callosum in schizophrenia with MR imaging. Acta Psychiatrica Scandinavica, 72, 414-421.

Nasrallah, H. A., Andreassen, N. C., Coffman, J. A., Olson, S. C., Dunn, V. D., Erhardt, J. C., \& Chapman, S. M. (1986). A controlled magnetic resonance imaging study of corpus callosum thickness in schizophrenia. Biological Psychiatry, 21, 274-282.

OKamoto, K., ITo, J., \& Tokiguchi, S. (1990). The MR findings of the corpus callosum in normal young volunteers. Nippon Igaku Hoshasen Gakkai Zasshi, 50, 954-963.

O'Kusky, J., Strauss, E., Kosaka, B., Wada, J., Li, D., Druhan, M., \& Petrie, J. (1988). The corpus callosum is larger with right-hemisphere cerebral speech dominance. Annals of Neurology, 24, 379-383.

Raine, A., Harrison, G. N., Reynolds, G. P., Sheard, C., Cooper, E., \& MEDLEY, I. (1990). Structural and functional characteristics of the corpus callosum in schizophrenics, psychiatric controls, and normal controls. Archives of General Psychiatry, 47, 1060-1064.

RAZ, N. (1994). [Age-related differences in human corpus callosum]. Unpublished raw data.

Raz, N., Spencer, W., Torres, I. T., \& Acker, J. D. (1990). Sex and age-related differences in midsaggital areas of the cerebral cortex and corpus callosum: An MRI investigation. Society for Neuroscience Abstracts, 16, 1160.

Simon, J. H., Schiffer R. B., Rudick, R. A., \& Herndon, R. M. (1987). Quantitative determination of MS-induced corpus callosum atrophy in vivo using MRI imaging. American Journal of Neuroradiology, 8, 599-604.
Steinmetz, H., Jancke, L., Kleinschmidt, A., Schlaug, G., VolkmanN, J., \& Huang, Y. (1992). Sex but no hand differences in the isthmus of the corpus callosum. Neurology, 42, 749-752.

Takeda, S., Yamada, S., Ono, S., \& Matsuzawa, T. (1988). Age-related changes in the size of the CC. Nippon Ronen Igakkai Zasshi, 25, 292-295.

Uematsu, M., \& KaIYA, H. (1988). The morphology of the corpus callosum in schizophrenia: An MRI study. Schizophrenia Research, 1, 391-398.

WEBER, G., \& WEIS, S. (1986). Morphometric analysis of the human corpus callosum fails to reveal sex related differences. Journal für Hirnforschung, 27, 237-240.

Weis, S., Kimbacher, M., Wenger, E., \& Neuhold, A. (1993). Morphometric analysis of the corpus callosum using MR: Correlation of measurements with aging in healthy individuals. American Journal of Neuroradiology, 14, 637-645.

Weis, S., Weber, G., Wenger, E., \& Kimbacher, M. (1988). The human corpus callosum and the controversy about a sexual dimorphism. Psychobiology, 16, 411-415.

Witelson, S. F. (1989). Hand and sex differences in the isthmus and genu of the human corpus callosum: A postmortem morphological study. Brain, 112, 799-835.

Witelson, S. F. (1991). Sex differences in neuroanatomical changes with aging. New England Journal of Medicine, 325, 211-212.

Woodruff, P. W., Pearl.son, G. D., Geer, M. J., Barta, P. E., \& ChIlcoaT, H. D. (1993). A computerized magnetic resonance imaging study of corpus callosum morphology in schizophrenia. Psychological Medicine, 23, 45-56.

YoshII, F., \& DUARA, R. (1989). Size of the corpus callosum in normal subjects and patients with Alzheimer's disease. Magnetic resonance imaging study. Clinical Neurology, 29, 1-7.

\section{NOTE}

1. Two publications were considered to contain more than one study. Clarke, Kraftsik, Van der Loos, and Innocenti (1989) contained postmortem and MRI data that were treated as two different studies and denoted as Clarke et al. (1989a) and Clarke et al. (1989b). Similarly, area measures from normal volunteers and pseudoneurological controls included in Raz, Spencer, Torres, and Acker (1990) were treated as separate studies (Raz et al., 1990a and 1990b, respectively).

(Manuscript received May 24, 1994; revision accepted for publication April 18, 1995.) 